\title{
Research for leachables of nuclear grade cation exchange resin
}

\author{
Liang-Cheng Chen*, Dah-Yu Kao, Tung-Jen Wen, Ping-Ji Huang
}

Institute of Nuclear Energy Research, Atomic Energy Council, Taiwan

\begin{abstract}
In power plants, the organic compounds which are leached from Cation Exchange Resin (CER) flowed into the reactor would decompose the component of $\mathrm{SO}_{4}{ }^{2-}$ and $\mathrm{Cl}^{-}$, which affect the water quality. Furthermore, the concentration of Total Organic Carbon (TOC) leaching is depends on the properties of resin. Prior to use, TOC and sulfate concentrations leached from CERs must be reduced in order to meet established standards generally; however, this entails an extended purification process and heavy use of water resources if quality problems are identified in the CERs. This study therefore investigated the leachates of commercial resins in order to establish a reference for the quality of deep bed CERs. In this report, Gel Permeation Chromatography (GPC) and Ion-Pair Chromatography (IPC) were used to identify molecular peaks in the CER leachables in order to elucidate the molecular distributions. We also sought to determine TOC and post-UV treatment sulfate concentrations using long-term soaking tests, in which the solutions of soaked resins were drained off for analysis on a daily basis. We also employed hydrogen peroxide to accelerate the aging process associated with decomposition in soaking tests in order to determine the stability of the resins. The series of analyses would assist us in understanding the properties of resin and the results can assist in power plants to improve water quality.
\end{abstract}

Keywords: Cation exchange resins, total organic carbon, leachables

\section{Introduction}

The principal role of a condensate polishing system is to purify boiler water. Through this system, the impurities and corrosion products can be reduced to improve water quality. Ion exchange resins have been used in condensate polishing for more than 50 years, and their quality and performance are relevant to boiler water purity. According to previous reports [1], [2], organics released from Cation Exchange Resins (CERs) are considered to be the main source of boiler water sulfate. These organic compounds may deposit on surface of the heat exchanger and which may reduce heat efficiency [3]. In addition, these organics decompose to sulfate under radiation and high temperatures, and the sulfate promotes Intergranular Stress Corrosion Cracking (IGSCC).

To date, there is not a standardization of analytical methods for resin leachable TOC testing. TOC leaching rate depends on the soaking conditions including temperature, oxidizing agent addition, catalyst addition, and so on. Generally, resin leachable TOC can be measured by either the soaking test or the loop test. The soaking test is characterized by simple analytical methods. As long as the resin is immersed in the water for a sufficient amount of time, the TOC concentration can be determined by removing and analyzing the soaking liquid [4]. The problem with this method is that its detection result is higher than actual NPP TOC concentrations. The loop test involves flowing water through the resin and analyzing TOC concentration. This method is able to simulate the actual operating conditions of power plant condensate demineralizer systems. The addition of oxidizing agents and catalysts can accelerate the resin

\footnotetext{
* Manuscript received March 14, 2015; revised July 23, 2015.

Corresponding author. E-mail address: srwalphag@iner.gov.tw.

doi: $10.12720 /$ sgce.4.2.112-118
} 
degradation process, allowing the evaluation of resin stability.

Leached organics from resins flow into reactor, where they are decomposed to sulfonic acid and chloride products due to the effects of high temperature. Therefore, UV lamp oxidation is a useful method to oxidize and decompose leachable organics to determine sulfonic acid and chloride concentrations. With the exception some extra high-energy bonds, nearly all of the chemical bonds can be damaged by $\mathrm{UV}$ at a wavelength of $185 \mathrm{~nm}$. Thus, UV irradiation could decompose leachable organics into $\mathrm{Cl}^{-}$and $\mathrm{SO}_{4}{ }^{2-}$ if chlorine and sulfur are contained in the organics. Therefore, the use of a $185 \mathrm{~nm}$ UV lamp to irradiate the resin leachate and conduct anion analysis is helpful to quantify $\mathrm{Cl}^{-}$and $\mathrm{SO}_{4}{ }^{2-}$ formation when resin leachate flows through the feedwater as well as to assess the impact of the resin on the boiler water.

In this report, we characterize four brands of resin using a four-step procedure to facilitate the analysis of CER leachates. These analysis methods include GPC, IPC, TOC analysis and IC analysis following UV treatment. GPC and IPC are used to determine the molecular weight distribution of CER leachates, which can have a major impact on anion resin fouling and organic sulfonates. The surface capacity of the anion resin is generally exhausted when organics of high molecular weight pass through mixed-bed demineralizers [5]. TOC analysis can be used to determine the amount of leachates released from the CER; IC analysis following the completion of UV treatment can be used to determine sulfate concentrations in the leachates from CER. Despite similarities in the variations in TOC concentration and sulfate concentration after UV treatment, TOC provides direct knowledge regarding the amount of leachates without the need to perform post UV treatment. Nonetheless, TOC and IC analysis are both important. These results can assist in power plant to improve water quality.

\section{Experimental Materials and Method}

\subsection{Materials section}

(1) Three kinds of divinyl benzene (DVB; H content, 8\%) were used to form gel-type strong acid CERs. All of the DVBs are compositionally the same; however, the manufacturing processes are different.

(2) 4-Phenol sulfonic acid hydrate $(85 \%$, MW $174.17 \mathrm{~g} / \mathrm{mol})$ was purchased from TCI/America. 4Sulfobenzoic acid potassium salt (95\%, MW 240.27) was purchased from Sigma/Aldrich. Poly(styrene sulfonate) sodium salt (MW 210, 3420, and $10000 \mathrm{~g} / \mathrm{mol}$ ) was purchased from SigmaAldrich and used as a GPC and IPC standard.

\subsection{Analytical equipment}

(1) Hitachi 7000 HPLC system: injection volume: $50 \mu \mathrm{L}$; flow rate: $1.0 \mathrm{~mL} / \mathrm{min}$.

Column for IPC: Gemini C18 column $(100 \times 4.6 \mathrm{~mm})$; column temperature of $25^{\circ} \mathrm{C}$; mobile phase: $10 \mathrm{mM} \mathrm{NH}_{4} \mathrm{OH}$ and $\mathrm{pH}: 10.6$.

(2) GPC Detector: Waters 2489 UV/Vis.; wavelength of $210 \mathrm{~nm}$; pump: Waters 1515 Isocratic HPLC Pump; column: ULTRAHYDROGEL 250 PKGD; column temperature of $25^{\circ} \mathrm{C}$; mobile phase: $0.2 \mathrm{M} \mathrm{Na}_{2} \mathrm{SO}_{4}+10 \%$ acetonitrile; flow rate of $1.0 \mathrm{~mL} /$ $\min$.

(3) TOC Analyzer: O.I. 1010 type wet oxidation total organic carbon analyzer.

(4) Ion chromatography instrument: DIONEX DX800; mobile phase of $0.3 \mathrm{mM} \mathrm{NaHCO}+2.7 \mathrm{mM}$ $\mathrm{Na}_{2} \mathrm{CO}_{3}$.

(5) UV lamp with $185 \mathrm{~nm}$ wavelength.

\subsection{Methods}

\subsubsection{IPC test}

(1) Soak a resin using water to volume ratio of 1:1 for $24 \mathrm{~h}$. Sample and analyze the leachate.

(2) Soak another resin with $1.5 \%$ added hydrogen peroxide for $24 \mathrm{~h}$ and repeats the test. 


\subsubsection{GPC test}

(1) Soak a resin using water to volume ratio of 1:1 for $24 \mathrm{~h}$. Sample and analyze the leachate.

(2) Sample and analyze the leachable solution for 16 and 93 days.

(3) Soak another resin with $1.5 \%$ added hydrogen peroxide for 1 and 16 days and repeat the test.

\subsubsection{CER leachable TOC soaking test}

(1) Soak the resin with water and mix with a volume ratio of 1:1.

(2) Sample and change the soaking water every day. The total experimental period is 30 days.

(3) Analyze the resin leachable TOC and sulfate concentrations.oak another resin with $1.5 \%$ added hydrogen peroxide for 1 and $16 \mathrm{~d}$ and repeat the test.

(4) Replace the solvent (pure water) with $1.5 \%$ hydrogen peroxide and repeat the test.

2.3.4 UV oxidation test of CER leachate

(1) Connect the UV lamp to the extra pure water production machine. Continuously flush the tube for 510 min until the analyzed $\mathrm{TOC}, \mathrm{Cl}^{-}$, and $\mathrm{SO}_{4}{ }^{2-}$ values between the UV lamp inlet and outlet are very close.

(2) Dilute the resin leachate until the TOC concentration is in the range of $100-250 \mathrm{ppb}$.

(3) Import the sample with slight shaking to make sure the gas from the UV tube is removed.

(4) Turn on the UV lamp and irradiate the sample for $100 \mathrm{~min}$. Shake the tube slightly every $10 \mathrm{~min}$ to mix the solution.

(5) Turn off the UV lamp and carefully pour out the solution. Analyze the concentrations of TOC and $\mathrm{SO}_{4}{ }^{2-}$ using the TOC and IC analyzer.

Table 1. GPC data of resin leachable polymer peak \% $(\mathrm{Mp}>2300)$

\begin{tabular}{|c|c|c|c|}
\hline Polymer peak area (\%) & Resin A & Resin B & Resin C \\
\hline 1 day & 60.3 & 60.9 & 59.9 \\
\hline 16 days & 51.0 & 59.2 & 57.4 \\
\hline 93 days & 45.5 & 57.2 & 53.4 \\
\hline
\end{tabular}

\section{Results and Discussion}

\subsection{GPC and IPC analysis results}

The GPC test was calibrated by three poly (styrene sulfonate) sodium salt standards with molecular weights of 210, 3420, and $10000 \mathrm{~g} / \mathrm{mol}$. Three commercially available DVB 8\% CERs (A, B, and C) were tested. The GPC spectra of the leachates from resins A, B, and C after soaking in pure water for 1 , 16, and 93 days are shown in Fig. 1. In Fig. 1, (a)-(c), corresponding to resins A-C, and the numbers attached with the peaks mean molecular weight which are estimated by standards. The Mp (molecular peak) used to separate oligomers and polymers is defined as $2300 \mathrm{~g} / \mathrm{mol}$. The polymer percentages of all resins calculated from the GPC spectra are shown in Table 1 . The polymer fraction was determined by integrating the curves in Fig. 1 from zero to a retention time corresponding to $2300 \mathrm{~g} / \mathrm{mol}$. The polymer peak area of resin A decreased more than those of the other resins. When resin A was soaked in water, the leachable polymer at $4948 \mathrm{Mp}$ was the highest in the first day and decomposed rapidly after 16 days. Even after 93 days, its signal area was still lower than the first day. The other signals at 3730, 1197, and $664 \mathrm{Mp}$ all decreased as soaking time increased from 1 to 16 days, but reached the highest levels at day 93. Thus, it seems that the leachable polymer at $4948 \mathrm{Mp}$ decomposed gradually. The GPC spectrum of resin B is similar to that of resin C. The four signals at 4956, 3900, 1196, and $850 \mathrm{Mp}$ in the spectrum of resin $\mathrm{B}$ increased in a normal fashion from day 1 to day 93. The polymer percentages were determined according to the ratio between polymer area and the total area of the signal. The polymer peak area percentage of resin A decreased significantly from day 1 to day 16 (Table 1). Their four Mp signals are all decreased especially $4948 \mathrm{Mp}$ in the 16th day. The differences in polymer peak area percentages among the other resins (B and C) from day 1 to day 16 were not significant; these resins appeared to be more stable than resin A. 


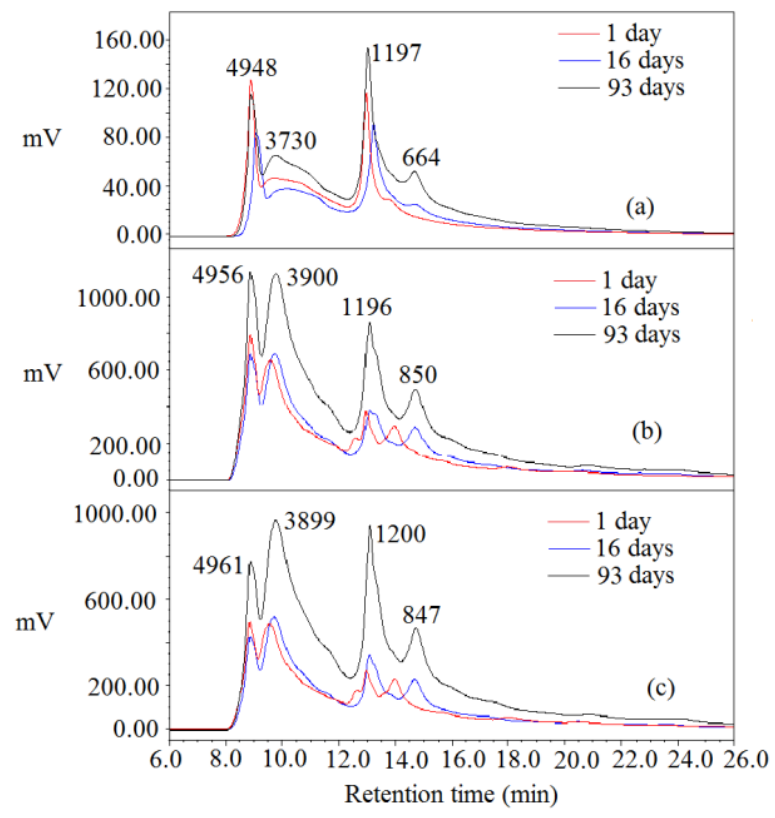

Fig. 1. GPC spectra of resins A, B, and C.

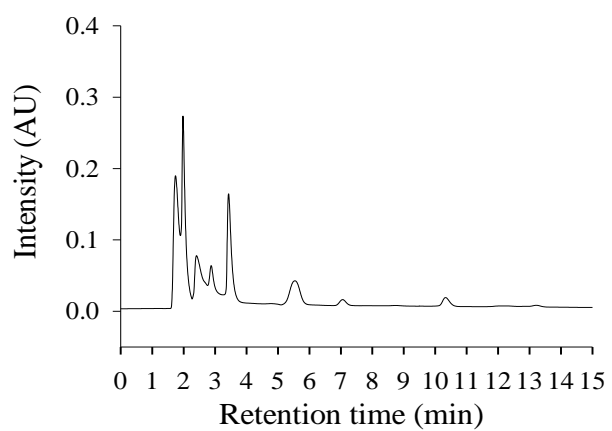

(a)

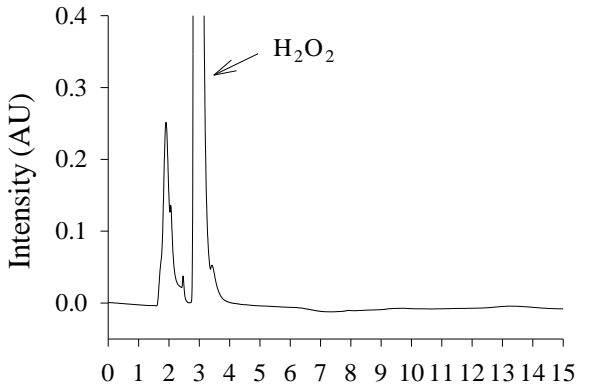

Retention time (min)

(b)

Fig. 2. IPC spectra for resin A soaked in (a) pure water and (b) $1.5 \% \mathrm{H}_{2} \mathrm{O}_{2}$.

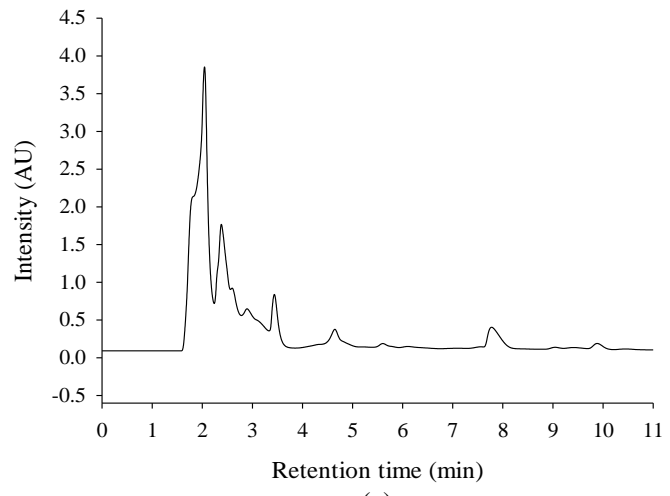

(a)

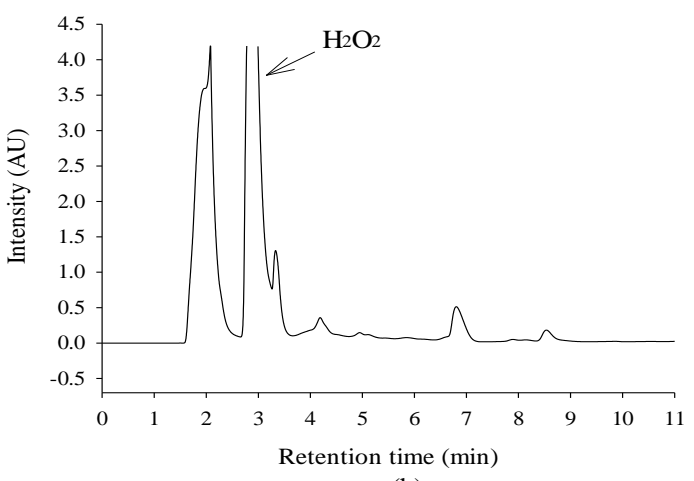

(b)

Fig. 3. IPC spectra for resin B soaked in (a) pure water and (b) $1.5 \% \mathrm{H}_{2} \mathrm{O}_{2}$. 
IPC was employed along with a standard sample to separate monomers and polymers. After calibrated using the standard, the following two monomers were separated from the polymers: 4-sulfobenzoic acid (4-SBA), retention time $=1.8 \mathrm{~min}$; and 4-phenol sulfonic acid (4-PSA), retention time $=2.1 \mathrm{~min} .4$ phenolsulfonic acid and 4-sulfobenzoic acid are the main monomer components in generally [6], [7].The monomer fraction was determined by integration of the curves in Fig. 2 from zero to the retention time $2.1 \mathrm{~min}$.

The IPC spectra of resins A and B IPC after soaking in water and $1.5 \%$ hydrogen peroxide are shown in Fig. 2 and Fig. 3, respectively. Hydrogen peroxide retention time in the IPC test is about 2.94 min. Fig. 2 shows that the polymer signals almost disappeared after resin A was soaked in hydrogen peroxide. The polymer signals of resin B also decreased after soaking with $1.5 \%$ hydrogen peroxide (Fig. 3). This indicates that the resin leachable polymers are more susceptible to interference from hydrogen peroxide, resulting in the release of sulfate.

To explain why the resin A polymer peak area at $4948 \mathrm{Mp}$ increased after the first day, the IPC data is shown in Table 2. The monomer peak area of resin A increases more rapidly than any other CER from day 1 to day 93. This might explain why the leachable polymer peak area of resin A increases more slowly than for the other resins. Furthermore, the GPC spectra do not show leachable monomer peaks; fortunately, GPC and IPC spectral results can be analyzed complementarily.

Table 2. IPC data of resins leachate monomer \% after different soaking times

\begin{tabular}{|c|c|c|c|}
\hline Monomer peak \% & Resin A & Resin B & Resin C \\
\hline 1 day & 100 & 100 & 100 \\
\hline 16 days & 735 & 101 & 111 \\
\hline 93 days & 1384 & 191 & 255 \\
\hline
\end{tabular}

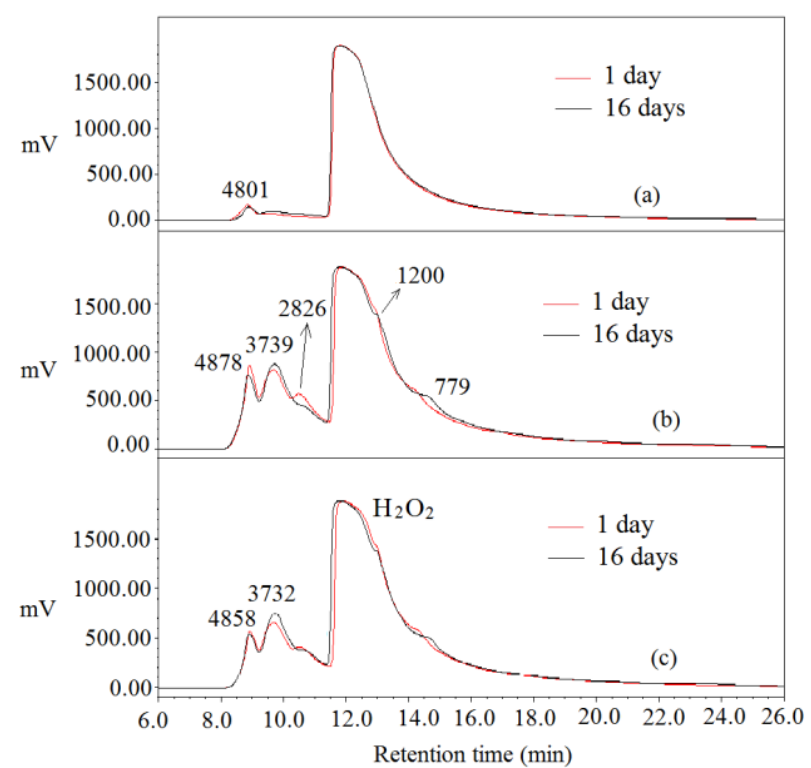

Fig. 4. GPC spectra of resins $\mathrm{A}, \mathrm{B}$, and $\mathrm{C}$ soaked in $1.5 \% \mathrm{H}_{2} \mathrm{O}_{2}$.

Fig. 4 shows the GPC spectra of resins A, B, and $\mathrm{C}$ after soaking in $1.5 \% \mathrm{H}_{2} \mathrm{O}_{2}$. Between 0 and 11.5 minutes, the signal strength of resin A was lower than that of other resins; therefore only resin A presents a particularly low peak area, while those of the other CERs are similar. Except for resin A, all other spectra present three polymer molecular peaks. Although $\mathrm{H}_{2} \mathrm{O}_{2}$ interferes with oligomer signals, oligomer molecular peaks approximately 1200 and $779 \mathrm{Mp}$ are still observed, except in the spectrum of resin A. This phenomenon may be explained by the unstable polymer structure of resin A due to deterioration by 
$\mathrm{H}_{2} \mathrm{O}_{2}$, which decomposes almost all leachable polymers. Unfortunately, the oligomer Mp signal overlaps with the $\mathrm{H}_{2} \mathrm{O}_{2}$ peak, and the polymer and oligomer peak area percentages cannot be compared as in the case of soaking in water. Fig. 4 shows that the total peak area (either polymers or oligomers) of resin A is far less than those of the other CERs.

\subsection{Cation exchange resin soaking leachate analysis results}

The soaking leachate TOC analysis results after soaking the CERs in pure water are shown in Fig. 5(a). The leachate TOC concentration of resin A is the lowest; however, the characteristics of this resin are unstable, and the TOC concentration increases obviously after about 20 days. Fig. 5(b) shows the TOC analysis results of leachates from CERs soaked in $1.5 \% \mathrm{H}_{2} \mathrm{O}_{2}$. The leachable TOC concentration of resin $\mathrm{A}$ is the highest after about 10 days. Hydrogen peroxide oxidizes the resin leachate; therefore, the TOC concentrations dropped after longer soaking times. The GPC results indicate that the polymers of resin A are almost all degraded after soaking with $1.5 \% \mathrm{H}_{2} \mathrm{O}_{2}$; thus, this resin should have the highest TOC concentration.

The changes in CER leachable sulfonic acid concentrations after UV irradiation are shown in Fig. 6(a). After soaking in pure water, resin A exhibited the lowest sulfonic acid concentration. After 20 days, the concentration began to rise. The results of decomposition experiments with $1.5 \% \mathrm{H}_{2} \mathrm{O}_{2}$ are shown in Fig. 6(b). The concentration of sulfonic acid in the leachate of resin A is the highest at almost all experimental times. This result can be explained by the IPC data, which indicated that almost all polymers in the resin A leachate are paired with sulfate, leading to the release of a large amount of sulfonate into solution. The other resins do not exhibit the same effect. In summary, poor resin quality may not be fully apparent from short-term tests of leachable TOC and sulfonic acid concentration. To determine resin quality in the short term, the adding of $\mathrm{H}_{2} \mathrm{O}_{2}$ to accelerate the deterioration process can be used as an auxiliary method.

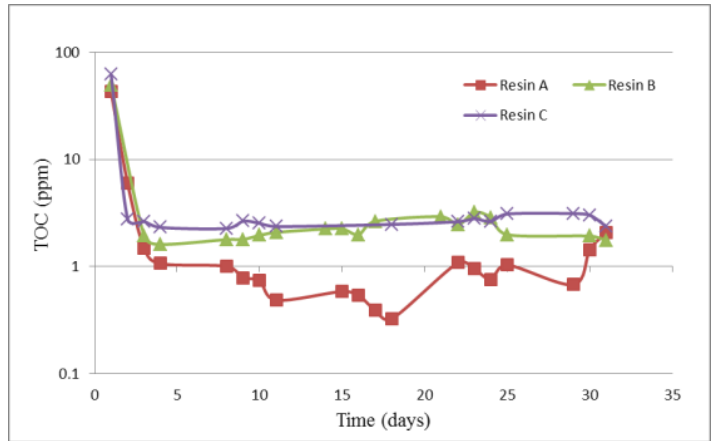

(a)

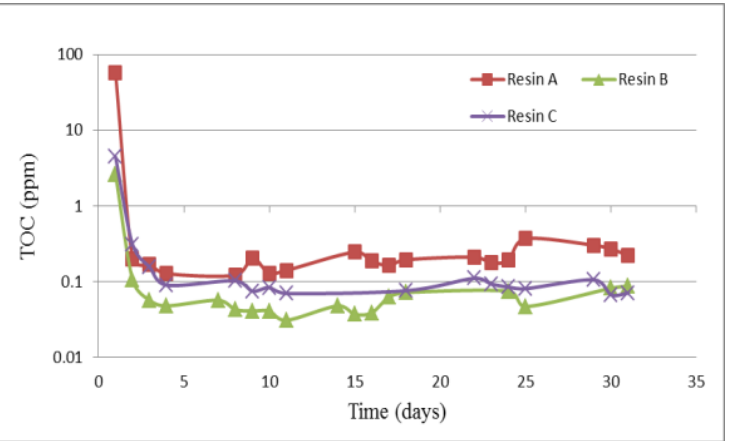

(b)

Fig. 5. Leachable TOC concentrations for CERs soaked in (a) pure water and (b) $1.5 \% \mathrm{H}_{2} \mathrm{O}_{2}$.

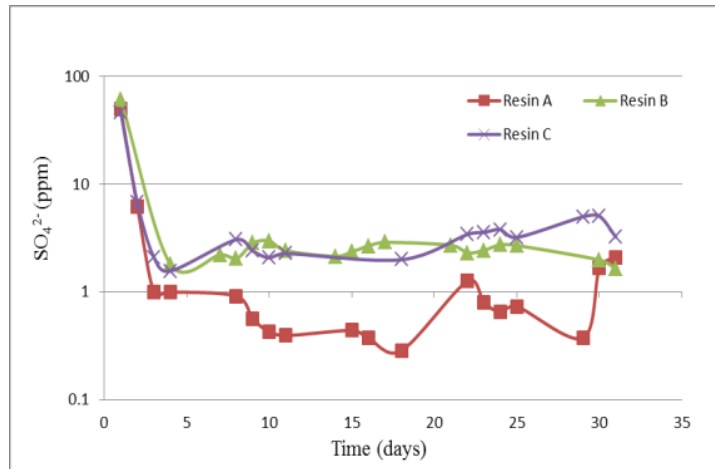

(a)

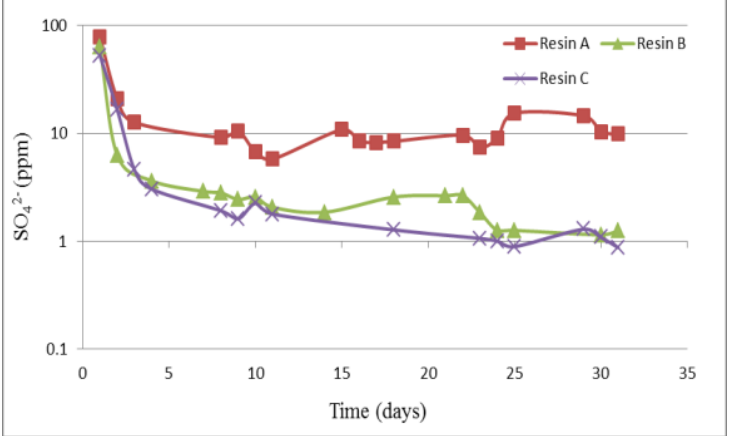

(b)

Fig. 6. Post-UV treatment leachable sulfate concentrations for CERs soaked in (a) pure water and (b) $1.5 \% \mathrm{H}_{2} \mathrm{O}_{2}$. 


\section{Conclusion}

The analysis of the GPC and IPC data indicated that the leachate of resin A was significantly different than the other resin leachates. Particularly when $\mathrm{H}_{2} \mathrm{O}_{2}$ was added, the experimental results for resin A were very different from those of the other resins. The usefulness of chromatographic methods in determining the characteristics of different resin leachates analyze was demonstrated in this case.

Although the TOC and post-UV treatment sulfate concentrations of resin A were the lowest during the water soaking test, it still consumes a considerable amount of water and requires many cleanings when it is used in actual power plant condensers. After soaking in $1.5 \% \mathrm{H}_{2} \mathrm{O}_{2}$, the TOC and post-UV treatment sulfate concentrations of resin A generally increased, indicating that resin $\mathrm{A}$ is unstable and of suspect quality.

Based on the chromatographic and long-term leachate analysis results, resin A seems to be significantly different from the other resins. Unfortunately, almost all tests normally used to evaluate resin leachates are short-term tests, and these tests are all easily passed. Incorporating the addition of $\mathrm{H}_{2} \mathrm{O}_{2}$ into the testing protocol could improve the leachable test specifications. This method can effectively shorten the experimental time by deteriorating the resin, allowing the accurate determination of resin quality.

\section{References}

[1] Maeda K et al. Behavior of impurites in BWR primary system water and suppression techniques. The Thermal and Nuclear Power, 1997;48:36-41.

[2] Maeda K, Kinoshita K. The relationship between the reactor water sulfate ion concentration and cation exchange resin of $\mathrm{CD}$ in BWR. Water Chemistry of Nuclear Reactor System. 2001;8:465-470.

[3] Gray DM. Measuring organics in power plants to prevent fouling, corrosion, and depositions. Ultrapure Water. 2007;24:25-27.

[4] Agui W, Takeuchi M, Abe M, Ogino K. Leachable from strong acid cation exchange resins. J. Jpn. Oil. Chem. Soc. 1988;37:1114-1120.

[5] Cutler FM. Measurement of cation resin extractables. Ultrapure Water. 1988;5:40-48.

[6] Stahlbush JR et al. Prediction and identification of leachables from cation exchange resins. In: Proc. of $48^{\text {th }}$ Int. Water Conf. Pittsburgh, 1987.

[7] Stahlbush JR, Storm RM. A decomposition mechanism for cation exchange resins. Reactive Polymers. 1990;13:233-240. 